\title{
HOMENS, VIOLÊNCIA DE GÊNERO E ATENÇÃO INTEGRAL EM SAÚDE ${ }^{1}$
}

\author{
Edna Granja e Benedito Medrado \\ Universidade Federal de Pernambuco, Recife, Brasil
}

\begin{abstract}
RESUMO: Este trabalho se insere no campo de discussões sobre violência de gênero, tendo como objeto de estudo o jogo discursivo de profissionais que atuam na rede de enfrentamento à violência contra as mulheres. Nosso objetivo é identificar como esses profissionais se posicionam acerca das possibilidades de atendimento a homens autores de violência, no Sistema Único de Saúde (SUS). Foram identificadas 38 instituições, nas quais realizamos observações e entrevistas semi-estruturadas com 55 profissionais que atuam diretamente na rede de prevenção, assistência e enfrentamento da violência doméstica e familiar contra a mulher no Recife, constituindo-se assim em nossos informantes-chave. A análise envolveu tanto a identificação dos repertórios como mapeamento das matrizes discursivas. A análise apresenta reflexões sobre alternativas de atendimento a esses homens, considerando eventos, condições de possibilidades, problematizando o lugar desse atendimento entre as estratégias transformadoras das práticas que dão sustentação à violência de gênero.
\end{abstract}

PALAVRAS-CHAVE: violência; gênero; integralidade; masculinidades; construcionismo.

\section{MEN, GENDER VIOLENCE AND COMPREHENSIVE HEALTH CARE}

ABSTRACT: This paper concerns gendered violence in relation to healthcare. Its focus is to examine the discourse of healthcare professionals who work to prevent, confront and assist in cases of violence against women, about the possibility of attending to male perpetrators of violence in the public health system (Sistema Único de Saúde - SUS). Our methodological resources consisted of observations and semi-structured interviews with 55 health professionals from 38 services and entities concerned with the prevention, treatment and management of intrafamilial and domestic violence in the city of Recife (NE, Brazil). We analysed discursive repertories and discursive matrix, based on the constructionism approach. From the analysis of these interviews, we sought to reflect on the alternatives of attending to male perpetrators of violence, considering events, conditions and the issue of the place of this attendance within the strategies for transformation of practices which sustain gendered violence.

KEYWORDS: violence; gender; integrality; masculinities; constructionism.

Mulheres, parceiros, incidências e resistências no campo da violência de gênero parecem ser apenas alguns nós de uma rede de processos multidirecionais que, hoje, apresentam a violência como um problema público altamente complexo. Classificado mais recentemente como um problema de segurança pública e justiça, portanto, alvo de medidas, sobretudo, punitivas, este problema vem sendo considerado também como de saúde e de direitos humanos. Nesse campo situamos a discussão desenvolvida neste artigo.

$\mathrm{O}$ encontro com as ideias feministas pode ser considerado como um ponto de partida para essas reflexões. Tal encontro foi marcado por identificação com grande parte dessas ideias, sobretudo a que reconhece gênero como uma (talvez a mais forte) das dimensões da desigualdade social, à medida que a relação entre masculino e feminino em nossa sociedade estruturase na diferença, mas especialmente na desigualdade (Barbieri, 1993; Scott, 1995).
Com esse encontro e com as identificações decorrentes, podemos afirmar que "óculos" foram construídos e colocados! Referimo-nos ao ato de colocar os óculos como um movimento de olhar para os acontecimentos sociais de forma intencional; um posicionamento reflexivo marcado por determinado pressuposto: as relações de gênero, caracterizadas por desigualdades, organizam a nossa sociedade. Contudo, em meio a tantas identificações, é preciso sinalizar também o estranhamento diante de uma narrativa que surge, no espaço desse encontro, como naturalizada: se a violência de gênero é crime, ao homem, nomeado agressor,$^{2}$ cabe apenas punição, a prisão.

A filiação à perspectiva construcionista de estudo das práticas discursivas (Gergen, 1994; Ibañez, 1994; Spink, 2004; Spink \& Medrado, 1999), como abordagem teórico-metodológica e também como "óculos", favoreceu a elaboração de alguns questionamentos éticos e conceituais sobre os possíveis efeitos da naturalização dessa 
narrativa. Consequentemente, incitou-nos a reflexões sobre a eficácia dessa estratégia diante do enfrentamento da problemática da violência de gênero.

Tal abordagem questiona o que é considerado como objeto natural, radicalizando com a natureza social do mundo vivido e a historicidade das nossas práticas. Dessa forma, é possível colocar em dúvida algumas narrativas apresentadas como naturais, tais como o lugar do homem e o que lhe cabe, diante de uma situação de autoria de violência. Logo, torna-se relevante compreender como essas ideias emergem na matriz de eventos que é sua condição de possibilidade. $\mathrm{O}$ estranhamento diante da referida narrativa e a tentativa de compreender os processos que dão sustentação a essa matriz é percebida, portanto, como caminho para a libertação de uma verdade já instituída e abertura de outras possibilidades para o enfrentamento do problema da violência.

$\mathrm{Na}$ condição de pesquisadores e, assim, reconhecendo-nos como parte desse campo, a aproximação com as discussões da saúde pública a partir de uma leitura psicossocial favoreceu o encontro com algumas perspectivas que podem subsidiar tanto o entendimento ampliado do fenômeno da violência de gênero como a construção de estratégias para o seu enfrentamento. Entre esses, destacamos a noção de integralidade em saúde.

Incluídas em todo movimento de formulação do Sistema Único de Saúde (SUS) e expressas na Constituição de 1988, em que a saúde é reconhecida como direito de todos e dever do Estado, as discussões sobre a integralidade e suas decorrências são percebidas como propulsoras de alternativas de um modelo de saúde fragmentado, desarticulado. Para o SUS a integralidade assumiu a condição de princípio doutrinário e de um modelo de ação, em um movimento sinalizador da complexidade e como um subsequente apelo à interdisciplinaridade.

Ao tentar transpor esse conceito para outros espaços, percebemos que, mesmo no âmbito da própria saúde, campo no qual havia sido gerado, existe um acentuado distanciamento entre o que se discute sobre integralidade e como ela se concretiza no cotidiano das políticas, dos programas e dos serviços (Hartz \& Contandriopoulos, 2004). Essa tensão teoria versus prática no campo de discussões sobre integralidade em saúde é profícua, tanto na produção acadêmica (Mattos, 2001, 2004) como no diálogo constante entre os profissionais e estudantes da área da saúde, que muitas vezes percebem que a prática cotidiana constitui em geral um sistema bem diferente do descrito nos livros e deliberado pelas legislações.

À luz dessas discussões sobre a integralidade, passamos a refletir sobre as limitações e possibilidades da efetivação do ideário do cuidado integral. Esse movimento foi deflagrado especialmente a partir da aproximação com a vivência de Centros de Atenção Psi- cossocial voltados a usuários de álcool e outras drogas (CAPS-ad), em sua maioria do sexo masculino.

Nesses CAPS-ad, conforme diálogo com profissionais que atuam direta ou indiretamente neste campo, ${ }^{3}$ recebem-se usuários encaminhados pela Vara Especial de Penas Alternativas. Entre as causas do encaminhamento, a partir do já referido "óculos", percebemos uma constante referência a atos de violência de homens direcionados às companheiras. Homens que chegam às Unidades com a prescrição de tratamento psicológico por um período determinado - geralmente um ou dois anos. $\mathrm{O}$ tratamento psicológico, direta ou indiretamente, parece ser entendido como pena, o que nos causa estranhamento, pois, apesar de sua presença no serviço ser devido a atos de violência, as propostas de tratamento focalizam apenas o uso problemático de drogas. Parece estar implícita nesse procedimento uma correlação direta e simplista entre o uso de drogas e a violência, desconsiderando os demais aspectos culturais e sociais que orientam a construção dos lugares dos homens e mulheres em nossa sociedade.

$\mathrm{O}$ uso de drogas e a violência parecem, sim, estar relacionados, porém não de uma forma simplista e causal. Alguns estudos apontam que o consumo de álcool e outras drogas está presente nos processos de socialização, em várias culturas, marcando a passagem do jovem para a vida adulta masculina. Segundo Nascimento (1999), essa passagem ocorre cada vez mais cedo: $50 \%$ da população masculina, entre 10 e 12 anos, já fizeram uso do álcool.

Pensar na integralidade em saúde estabelece-se assim como estratégico, no sentido de consolidar o reconhecimento desses atravessamentos, representados pela violência em sua complexidade - não só como um problema de justiça e segurança pública, mas também de saúde. Logo, optamos por direcionar esta pesquisa para a problematização do atendimento aos homens autores de violência, na perspectiva da integralidade em saúde.

Qual o lugar do atendimento a esses homens no SUS? Em quais serviços estão sendo atendidos? Como esses homens chegam ao Sistema? Como são acolhidos? Como esse acolhimento responde ao modelo de atenção integral à saúde? São inúmeras questões para as quais a literatura acadêmica sugere poucas respostas. Se a violência contra as mulheres é um dos assuntos de maior destaque nos meios de comunicação, ressaltando a importância da criminalização do homem autor de violência, parece que a pesquisa acadêmica tem contribuído pouco para a consideração desse homem como pessoa, em suas necessidades de saúde, de cuidado.

Lançando o olhar para o meio legislativo, é possível situar um importante marco, no percurso de desenvolvimento da presente pesquisa, que deu ainda 
mais visibilidade a essa lacuna de conhecimento, evidenciada pela pouca produção em torno da temática dos homens autores de violência: a aprovação da Lei Maria da Penha, em agosto de 2006. Em linhas gerais, a Lei orienta práticas institucionais de enfrentamento à violência doméstica e familiar contra as mulheres. Constituiu uma grande conquista dos movimentos sociais ligados às causas feministas e também uma resposta às críticas direcionadas à impunidade dos homens que cometem agressão.

Contudo, ao mesmo tempo em que acentua a punição para os homens autores de violência e traz em seu bojo medidas protetoras direcionadas às mulheres, a Lei possibilita também o encaminhamento desses homens para serviços de reabilitação e educação. No artigo 35 (das Disposições Finais), a Lei determina que a União, o Distrito Federal, os Estados e os Municípios poderão criar e promover, no limite das respectivas competências, entre outras coisas: "V - centros de educação e de reabilitação para os agressores". E, no artigo 45, prevê uma alteração no artigo 152 do Código Penal, que corresponde ao acréscimo do seguinte parágrafo: "Parágrafo único. Nos casos de violência doméstica contra a mulher, o juiz poderá determinar o comparecimento obrigatório do agressor a programas de recuperação e reeducação" 4 .

Afinal, que centros ou programas são esses? Eles compõem os serviços já voltados para a violência contra as mulheres? Qual é a relação desses serviços com o sistema de saúde? A aprovação da referida Lei, no período inicial desta pesquisa, trouxe transformações para o campo em discussão, favorecendo a construção de um novo lugar para os debates sobre a atenção aos homens autores de violência. Dessa forma, a aprovação dessa Lei pode ser apontada como incidente crítico no decorrer desse processo, à medida que resultou de (e ao mesmo tempo iniciou!) um momento de negociação de sentidos e de contestação do que está estabelecido, provocando práticas e, por conseguinte, possíveis transformações (Galindo, 1999).

Aqui é preciso estabelecer uma distinção entre a nomeação de violência de gênero, que temos utilizado na maior parte do texto, e a de violência contra as mulheres. A formulação e aplicação do conceito de gênero estão situadas, a partir da década de 1980, como tentativa de ampliar a compreensão sobre as diferenças e desigualdades entre os sexos. Se antes se entendiam tais diferenças como expressões de papéis sociais rígidos, condicionados culturalmente pelas diferenças biológicas entre homem e mulher, dentro da perspectiva de gênero focamos os aspectos sociais, não só indicando a construção social da relação desigual entre os sexos, como também dos lugares do feminino e do masculino na nossa sociedade (Santos \& Izumino, 2004).
Assim, esse trabalho aborda a compreensão reflexiva da violência de gênero. Para Saffioti (2004, p. 64), "a violência de gênero ocorre normalmente no sentido homem contra a mulher, mas pode ser perpetrada também por um homem contra outro homem ou por uma mulher contra outra mulher". O que está em cena, portanto, são as construções de masculinidades e feminilidades e os jogos performáticos de sujeitos (Butler, 2001) em conflito, que podem produzir, entre outras coisas, expressões de violência.

Todavia, as políticas sociais e a legislação atual parecem não considerar a violência como parte dessa complexidade relacional. O foco continua sendo as mulheres e, assim, coerente com esse direcionamento, temos políticas, legislações e, consequentemente, serviços voltados para a violência contra as mulheres, reafirmando a distinção sexual em detrimento da ordem de gênero. Dessa forma, o presente trabalho procurou compreender, sob a perspectiva da violência de gênero e a partir do enfoque da integralidade, qual o lugar do atendimento aos homens autores de violência nos serviços voltados para a violência contra as mulheres. Procuraremos ainda situar a referência desses serviços ao setor saúde, a partir da fala dos profissionais, e sinalizar sua localização no fluxo de processos e movimentos de enfrentamento da violência de gênero.

\section{Passo a passo}

Esta pesquisa é parte de um projeto mais amplo que está sendo desenvolvido pelo Núcleo de Pesquisas em Gênero e Masculinidades da UFPE. Inicialmente, buscamos mapear todos os serviços de atendimento a homens autores de violência, na cidade do Recife. Como tínhamos a informação de que esses serviços eram em número reduzido, resolvemos ampliar nossa busca englobando todas as instituições que atuam na rede de enfrentamento à violência de gênero, isto é, aquelas que tinham projetos ou ofereciam serviços voltados para homens e/ou mulheres em situações de violência de gênero.

Assim, foram realizados contatos com profissionais que trabalham em Organizações Não-Governamentais Feministas e Redes que historicamente atuam nessa problemática, profissionais vinculados à gestão pública, além de buscas via internet.

Tal mapeamento teve o objetivo de elaborar um panorama das instituições que lidam com essa problemática e, ao mesmo tempo, identificar aquelas que compõem o setor saúde. Foram localizadas 38 instituições $\mathrm{e}$, posteriormente, categorizadas a partir da forma como definem sua finalidade e estratégias de ação.

Como estratégia para conhecer melhor cada instituição, entender seu lugar na rede de serviços voltados 
para a violência contra as mulheres e perceber como (e se) faziam referência ao setor saúde, realizamos registros de observações do funcionamento da instituição. Posteriormente, foram feitas entrevistas semiestruturadas com profissionais das mesmas, realizadas sempre com a presença de dois pesquisadores vinculados ao Núcleo de Pesquisa.

As pessoas que seriam entrevistadas não estavam definidas, a princípio, sendo o contato para o preenchimento do Perfil Institucional e o registro das observações momentos importantes para tais decisões. Foram realizadas de uma a cinco entrevistas com profissionais por instituição, totalizando 55 entrevistas. A quantidade de entrevistas em cada instituição foi definida a partir da disponibilidade dos profissionais.

Todas as entrevistas foram transcritas de forma literal e à transcrição seguiu-se a leitura e discussão, para a organização coletiva das análises. Durante a leitura, foram sinalizados, no corpo da entrevista, os trechos que faziam referência ao setor saúde e continham argumentos dos entrevistados em relação ao atendimento aos homens autores de violência, bem como possibilidades de intervenção junto aos mesmos. Para tal marcação foram utilizadas duas cores distintas. Este processo foi realizado por dois pesquisadores distintos.

O passo seguinte foi a construção de dois quadros. O primeiro continha os trechos sinalizados com referências ao setor saúde, identificando em qual entrevista foi registrado e já antecipando a categorização do conteúdo temático do trecho destacado. O segundo, da mesma forma, trazia os trechos destacados referentes aos argumentos sobre atendimento aos homens autores de violência e a conformação do mesmo, para os entrevistados que o consideraram, ou não, necessário. O objetivo de sinalizar o conteúdo temático do trecho grifado foi começar a trabalhar na construção de categorias, a partir dos aspectos sinalizados no diálogo com os entrevistados.

Marca-se aqui mais um traço da abordagem construcionista em psicologia social. Ditar no início do processo as categorias nas quais se deverão enquadrar as respostas dos entrevistados poderia limitar o processo de análise discursiva. Seria incoerente definir, a princípio, categorias, já que elas não podem ser compreendidas de forma desvinculada do contexto de sua produção (Spink, 2004).

Dessa forma, a partir dos registros dos diálogos e da organização desses quadros foi possível elaborar dez focos de análise em relação ao setor saúde nos diálogos com os profissionais: serviços de saúde; saúde mental; lugar do serviço de saúde como estratégia de enfrentamento à violência contra as mulheres; ineficiência/ eficiência de recursos humanos e técnicos; intersetorialidade; Instituto Médico Legal (IML); controle social do Estado pelos movimentos sociais; participação protagonista das Organizações Não-Governamentais (ONG) na elaboração e implementação de políticas; espaços de saúde mental associados ao uso de drogas; Núcleos Acadêmicos e Clínicas Escola.

No que se refere ao tipo de atenção que deve ser oferecida aos homens autores de violência, foram elaboradas nove categorias: punição na forma de prisão; reeducação como punição; nada; reeducação como direito; prevenção; empoderamento das mulheres; políticas públicas para os homens; atenção psicológica/ psicossocial; atenção no modelo dos Alcoólicos Anônimos (AA). Os repertórios discursivos registrados se configuram como os eixos da análise desenvolvida. Da identificação desses repertórios, entendidos como as nomeações, argumentos, expressões, figuras de linguagem que demarcam as condições de possibilidades de produção de sentidos, cujos parâmetros são definidos pelo contexto em que essas práticas são produzidas e consequentes gêneros discursivos (Spink \& Medrado, 1999, p. 47), partimos para uma compreensão mais ampla e integrada dos mesmos.

Em seguida, elaboramos algumas sínteses analíticas, tanto em relação ao lugar do setor saúde no enfrentamento da violência contra as mulheres como sobre as possibilidades de atendimento aos homens autores de violência, dentro do referido setor.

Todos os procedimentos referidos nesta dança metodológica tiveram uma preocupação ética que, não apenas no uso de ferramentas como na assinatura prévia do Termo de Consentimento Livre e Esclarecido e da Carta de Anuência, mas especialmente na postura adotada pelos pesquisadores, marcada pela disponibilidade para a escuta atenta e pelo cuidado para que a participação fosse genuína, voluntária e bem informada.

\section{A referência ao setor saúde e as possibilidades de atendimento aos homens autores de violência, na cidade do Recife}

Iniciando por uma análise descritiva dos serviços de saúde registrados, é importante destacar que eles estão classificados no agrupamento dos serviços de atendimento às mulheres e são em número de sete. Destes, cinco são maternidades, um se define como ambulatório voltado para a saúde da mulher e o último constitui um serviço de referência para mulheres em situação de violência, dentro de um hospital geral.

Considerando o fluxo interno, parece que a definição dos procedimentos adotados nos serviços de saúde encontra-se permeada por algumas questões sobre as quais é possível refletir. A primeira se refere à situação dos procedimentos voltados para a violência contra as 
mulheres, dentro dos serviços. Considerados parte de um serviço maior, eles se encontram, em alguns casos, isolados dentro de salas ou setores, ou ainda, como propriedade de determinado profissional, que centraliza o conhecimento e a execução de procedimentos frente a esse problema.

Tal dificuldade pode ser percebida como um furo e sinaliza alguns obstáculos à concretização da integralidade. Segundo Souza Leão (2005), estaria em jogo, nessas situações, um comprometimento do que é considerado integralidade focalizada. A autora refere que essa dimensão abrange práticas e interlocuções entre a equipe interdisciplinar, no espaço singular dos serviços. Nesse sentido, é importante considerar que o espaço singular de cada serviço está organizado a partir das recomendações e relações com o espaço mais amplo, que o situa em uma Rede. Todavia, esse espaço mais específico do serviço tem autonomia e capacidade para criar um lugar em que a integralidade seja consolidada. Cecílio (2001) afirma:

O resultado dessa integralidade focalizada há de ser o resultado do esforço de cada um dos trabalhadores e da equipe como um todo. Cada atendimento, de cada profissional, deve estar compromissado com a maior integralidade possível, sempre, mas também ser realizado na perspectiva de que a integralidade pretendida só será alcançada como fruto do trabalho da equipe de saúde, com seus múltiplos saberes e práticas (p. 16).

É possível pensar em dois outros fatores que podem dificultar a manutenção do fluxo interno. $\mathrm{O}$ primeiro refere-se ao fato de que a violência de gênero não chega às unidades de saúde como queixa principal, parece ser indicada apenas no curso do atendimento. $\mathrm{O}$ segundo aspecto que interfere na fluidez dos procedimentos dentro e fora da unidade é a composição, a capacitação e a experiência da equipe para atuar diante da violência de gênero. Ao perguntar como as equipes foram preparadas para intervir nessas situações, foi acessada uma informação, segundo a qual as maternidades compõem uma rede de referência do Programa de Enfrentamento à Violência contra as mulheres, lançado ainda em 2004.

As falas de algumas profissionais entrevistadas indicam que, nessa época, uma Organização nãogovernamental promoveu, em parceria com a Secretaria de Saúde, um curso de capacitação para alguns profissionais da Rede. Foram indicados, nos serviços, os profissionais que participariam e, posteriormente, teriam a função de multiplicadores e promotores de ações para o enfrentamento da violência no âmbito desses serviços.

Aqui já é possível pensar no fluxo externo e nas possibilidades de ações articuladas em uma Rede de
Assistência, a partir da noção da saúde como sistema, na perspectiva da integralidade ampliada. Tal perspectiva compreende a integralidade a partir da articulação entre os serviços de saúde e entre estes e outros setores e instituições sociais. Trata-se das articulações em rede, entre as partes do sistema, seja porque as ferramentas que proporcionam saúde estão distribuídas em uma Rede de Serviços, seja porque a melhoria das condições de vida não se restringe ao setor saúde. Logo, o sistema de referência e contrarreferência não deve se restringir aos serviços de saúde, e, sim, abranger o encaminhamento para outros setores, como escolas, atividades laborativas, esportivas e de lazer (Cecílio, 2001).

Ao aludir aos serviços de saúde na Rede os profissionais citam outras instituições com as quais eles estão articulados: Instituto Médico Legal (IML), Centro de Referência, Delegacia e outras unidades de saúde, tais como: postos de saúde da família e policlínicas. Não é possível identificar, na fala, um fluxo preciso. O mesmo parece variar em função do caso atendido e, sobretudo, da proximidade entre as instituições. Entretanto, o Centro de Referência parece mesmo ser posicionado, pelos profissionais, como o grande "guarda-chuva" para a assistência nos casos de violência de gênero, sendo também sinalizada, pelos entrevistados, a sobrecarga do equipamento.

Outra questão relevante é que os serviços de saúde, ao que parece, ainda não são a porta de entrada para os casos de violência de gênero. Parece que o reconhecimento dos casos de violência é correlato à identificação de um dano físico. Portanto, as equipes parecem estar mais preparadas para receber casos de violência sexual, pois, para os possíveis danos de ordem física acarretados pela mesma há um procedimento claro, que vai da profilaxia contra determinadas doenças aos atendimentos psicossociais previstos, a priori. $\mathrm{O}$ que leva a uma remota discussão sobre o modelo de saúde centralizado na doença, no comprometimento físico, bastante criticado.

Contudo, é importante ir além da crítica e perceber que a expectativa dos usuários e a forma como os serviços são estruturados interagem dialogicamente. Se o serviço de saúde é o espaço da doença, do comprometimento físico, e a violência nem sempre gera esse tipo de dano, a procura por tais serviços só ocorrerá nos casos em que o dano for mais evidente. Da mesma forma, à medida que os usuários não elegem as unidades de saúde como os espaços para onde devem levar a queixa da violência e assim procurar ajuda, estes serviços não se estruturam para tal.

O mapeamento confirma, assim, uma centralização das instituições voltadas para o enfrentamento da violência de gênero ainda no setor de Justiça e Segurança Pública, por um lado, e nos movimentos sociais 
e espaços de organização política construídos pelos mesmos. Ratificou, ainda, uma afirmativa inicial de que, tanto as políticas quanto os serviços são voltados para as mulheres, em detrimento de uma perspectiva de gênero, na qual os homens também fossem considerados em suas necessidades de cuidado e este fato passasse a ser percebido como estratégico para a superação do problema da violência de gênero.

A referência a serviços de saúde $\underline{5}$ compõe as falas dos profissionais, que parecem reconhecer alguns serviços como nós da rede de enfrentamento à violência contra as mulheres. Além disso, a menção a esses serviços vem acompanhada da constatação de que Recife dispõe de uma Rede nesta área, sobretudo quando comparado a municípios vizinhos.

Contudo, o reconhecimento da existência de uma Rede não pode ser visto como uma afirmação da adequação da mesma. É possível perceber alguns repertórios que apontam um posicionamento crítico diante da discussão sobre a eficiência/ineficiência de recursos humanos e técnicos. Diante das carências apontadas, um componente importante desse contexto, que surge na fala dos profissionais, é a participação protagonista das ONG na formulação e implementação de políticas. Participação esta caracterizada pelo fato das organizações terem sido requisitadas, em alguns momentos, para a proposição de cursos de capacitações e de formação.

Um aspecto de relevância na reflexão que vem sendo desenvolvida é que mesmo com a quantidade significativa de instituições que constituem espaços de organização política, com a presença marcante de ONG, a referência ao controle social do Estado por parte dos movimentos sociais só é construída em um trecho, entre todas as entrevistas analisadas.

Convém ressaltar a importância do controle social, em um cenário no qual não só a ineficiência de certos serviços é perceptível, como também a própria noção de saúde implicada nas práticas dos profissionais que atuam nos serviços é bastante questionável. Como conceito de saúde, na referência a serviços, percebe-se, em alguns momentos, que o lugar do serviço de saúde é considerado como alternativa diante de situações de comprometimento físico. Dessa forma, atrelado à questão física, os profissionais sugerem que o serviço de saúde deveria ser a porta de entrada para as questões de violência contra as mulheres. Por outro lado, o lugar que surge como importante disparador de fluxos é o IML, à medida que se configura como o único lugar por onde a mulher, impreterivelmente, precisa passar, uma vez realizada a denúncia. É no IML que se realiza o exame de corpo de delito, fundamental para o encaminhamento do processo criminal.

Ao que parece, o lugar do atendimento psicológico ou psicossocial não está localizado na rede de saúde, e sim no Centro de Referência. As reflexões anteriores, nas quais o serviço de saúde aparece relacionado ao dano físico, podem sinalizar que o que estaria subsidiando esse não reconhecimento seria a compreensão de que agravos dessa ordem não trazem danos aparentes.

Contudo, convém lembrar que o Recife também possui uma rede de serviços de saúde mental, cujo referencial é o atendimento psicossocial: os Centros de Atenção Psicossocial - CAPS. Como aconteceu com o SUS, a formulação e implementação dos CAPS foram fruto de um movimento de questionamento sobre a forma como vinha se configurando a atenção à saúde mental no Brasil.

As falas dos profissionais atribuem um lugar secundário aos CAPS. Parece que os consideram como mais adequados para de transtornos mentais graves, $\mathrm{o}$ que dificulta o acesso a eles, em casos de homens e mulheres envolvidos em situações de violência. Ao mesmo tempo, essa é a única referência a Núcleos Acadêmicos e Escolas. A não referência a esses espaços causa estranhamento, uma vez que, em princípio, deveriam compor a Rede, já que sua existência decorre do compromisso não só com a formação dos profissionais como também com o atendimento à comunidade.

Já os CAPS só aparecem na Rede como espaços de saúde mental associados ao uso de drogas. Esse é o momento em que os sentidos da atenção ao homem começam a ser produzidos nas entrevistas, dando-lhe um lugar na Rede e, mais uma vez, relacionando violência, masculinidades e uso de drogas. Por conseguinte, o CAPS-ad é apontado como referência para encaminhamentos, sobretudo no âmbito da justiça. A fala de Clara,${ }^{6}$ profissional que trabalha no Juizado Especial Criminal, local onde eram julgados, na época (2006), os casos de violência doméstica e familiar antes da Lei Maria da Penha, possibilita algumas reflexões. A fala constitui a resposta para a pergunta sobre para onde são encaminhados os homens e ocorreu após Clara também relacionar a violência ao uso de drogas.

Clara: É, a gente encaminha para os Caps, Desafio Jovem, a gente tem algumas pessoas que estão indo lá, a gente não trabalha com... assim a gente evita o máximo encaminhar para o A.A. Porque o A.A. é grupo de apoio, não é um tratamento específico ...

Entrevistadora 1: Ok, e uma coisa, na verdade, duas. Uma é sobre a equipe e outra é... me chamou a atenção o Caps. Como é que se faz o encaminhamento para lá?

Clara: Não, eu não encaminho com o motivo, porque é muito complicado ... geralmente quando é pro Caps, eu coloco tratamento por uso e abuso de álcool, quando eu percebo que a pessoa tem esse uso abusivo, dependência química, quando eu vejo que 
a pessoa é dependente, aqui a gente tem como vê se a pessoa é mesmo dependente, em alguns casos, mas tem outros que a gente duvida se a pessoa realmente tem problema com álcool, porque a gente só tem uma entrevista aqui, ou vem só a ofendida e ela não diz a verdade. Às vezes, a ofendida só quer ferrar o cara, existe muito isso aqui.

Primeiro, é importante atentar para a forma como se dá a escolha da instituição para a qual será encaminhado um determinado caso. As preocupações da profissional incidem sobre a necessidade de controle e monitoramento da frequência do homem. Tal preocupação pode justificar-se diante do sentido do encaminhamento, uma vez que ele parte de um serviço de justiça, que dita medidas a serem cumpridas. É nesse âmbito que o tratamento psicológico, mesmo quando indicado, como em casos de dependência química, pode parecer ser associado à noção de pena. Ao mesmo tempo, pensando na noção da integralidade, na possibilidade de interligar redes, serviços, com o objetivo de garantir um cuidado integral, é questionável a convicção da profissional sobre não indicar o motivo do encaminhamento.

Talvez seja exatamente nesse momento que se instaura uma brecha no que parece ser a única possibilidade, ainda que enviesada, de entrada do homem na rede de enfrentamento à violência contra as mulheres. $\mathrm{O}$ homem entra no serviço com o rótulo de dependente químico ou, pelo menos, de usuário problemático de drogas, e o tratamento incide nesse ponto. A não identificação do motivo central do encaminhamento pode contribuir para a ausência de um trabalho mais reflexivo sobre as questões implicadas na autoria do ato de violência. Outra consequência é a negação de um espaço no qual o homem possa construir outros sentidos para a sua masculinidade.

Uma afirmação, direcionada às mulheres, de que elas não trazem a violência como queixa central a violência, pode ter seu sentido ampliado para os homens. A dificuldade de acesso já foi identificada e deve ser alvo de debates. Contudo, mesmo diante dela, falas como a de Clara indicam que o homem está chegando, sim, ao sistema de saúde. Todavia, acaba-se deslocando o foco, maquiando a demanda, e o que poderia constituir um espaço de atenção ao homem não se concretiza.

Do nada a fazer, passando pela punição, reeducação, chegando até a sinalização da necessidade de prevenção e políticas públicas para os homens, as considerações sobre o tipo de atendimento que deve ser oferecido aos homens são as mais variadas e parecem estar associadas ao lugar em que trabalha o profissional que as emite.

É preciso destacar aqui a recorrência a um discurso, ao que parece, ainda hegemônico no movimento feminista e presente na fala de profissionais não necessariamente vinculados à militância feminista, segundo o qual os esforços políticos não devem desviar o foco e, dessa forma, não é possível pensar em atendimento a homens autores de violência.

Assim, ao mesmo tempo em que aparecem propostas de cuidado por parte de alguns profissionais, é possível também perceber uma concentração dos usos de repertórios que sugerem esse nada a fazer entre os profissionais dos espaços de organização política. Nestes, o discurso referido como hegemônico dentro do movimento feminista parece ecoar de forma bastante significativa.

$\mathrm{O}$ nada a fazer surge junto à sinalização do empoderamento das mulheres como estratégia central de intervenção. $\mathrm{O}$ não considerar a possibilidade de um homem autor de violência poder localizar aquele ato na sua história, na sua constituição como pessoa e escolher construir outros sentidos para a sua condição pode indicar uma naturalização da violência como atributo do homem, reduzindo o autor ao ato. Nesse sentido, convém assinalar que essa forma de ver a constituição das pessoas destoa do apelo cultural e histórico do próprio movimento feminista, ao recontar a história de opressão das mulheres.

Aproxima-se dos repertórios que compõem esse nada a fazer, aqueles parecem ser utilizados para enfatizar a necessidade de punição na forma de prisão. Aqui é importante dar voz a um debate sobre o temor de que pensar na atenção aos homens autores de violência possa vir a minimizar o ato cometido, protegendo o homem, à medida que o posiciona como doente, que requer tratamento (Figueroa, 2004). Contudo, ao sugerirmos a ampliação do olhar para esses homens, não compartilhamos dessa perspectiva de vitimização, tendo em vista que a construção de um espaço de escuta não anularia a condução do processo judicial. E, sim, se somaria a ele.

É importante esclarecer, como dito anteriormente, que não se trata de uma fala homogênea. $\mathrm{O}$ tratamento psicológico, por exemplo, se inclui nesse contexto tanto na perspectiva de vitimização quanto na de pena, punição ou como estratégia de redução de pena frequentemente utilizada em processos judiciais. $\mathrm{E}$, em alguns casos, esses sentidos são presentificados, como marca dos arranjos dicotômicos, tais como homem e mulher, agressor e vítima. Isto é, à mulher, o tratamento psicológico e, aos homens, a punição.

Outro repertório utilizado de forma frequente é o da reeducação. Como dito, a utilização é frequente, porém, mais uma vez, não homogênea, surgindo nas falas tanto como punição quanto como direito.

Esses distintos usos, quando considerada a necessidade de algum tipo de atenção aos homens autores 
de violência, deram origem a diferentes concepções sobre a forma como deveria se estruturar essa atenção. O setor saúde é referido como possível espaço para promover a atenção a esses homens. A Secretaria de Saúde é presentificada como interlocutor privilegiado e possível desencadeador dessa ação.

A Lei Maria da Penha é lembrada nas falas, atrelada à possibilidade de atendimento, o que corrobora a condição de incidente crítico, na qual foi posicionada, no início do artigo. A partir dela parece que essa discussão foi reconfigurada. A busca por mecanismos de prevenção, presente na Lei, também está entre os repertórios produzidos pelos profissionais, associado à necessidade de formulação e proposição de políticas públicas voltadas para os homens.

É nessa perspectiva que a atenção ao homem autor de violência passa a ser concebida, seja no formato de atenção psicológica, seja na perspectiva de um modelo aproximado ao dos alcoólicos anônimos, mais uma vez ressaltando-se a correlação entre gênero, masculinidade e violência.

\section{Entre rupturas e permanências}

A história recontada no decorrer deste texto remete à tensão entre movimentos de resistência e narrativas instituídas. Uma primeira tensão pode ser percebida como decorrente dos sentidos que se expressam no uso de ditos populares, como o tão conhecido "em briga de marido e mulher, ninguém mete a colher". Trata-se de repertórios discursivos que tanto se expressam como são produzidos por tal uso e, assim, por muito tempo a violência de gênero ficou adstrita à esfera privada e familiar. É possível afirmar que tornar esse problema público e, portanto, alvo de políticas sociais, constitui uma ruptura de uma verdade instituída há muito tempo.

É importante assinalar que essa ruptura deu visibilidade a várias vozes que nos dias atuais alimentam as discussões sobre a violência. Contudo, no intuito de fortalecer um posicionamento, a ruptura também foi marcada pela instituição de outras verdades. As estratégias discursivas se direcionaram, por um lado, para a garantia de uma rede de assistência para as mulheres em situação de violência e, por outro, para a reivindicação de mecanismos mais rígidos para os homens autores. Institui-se, assim, a narrativa que fundamenta o posicionamento de parte do movimento feminista, que se coloca contrária a qualquer tipo de ação voltada para os homens.

Nesse ponto, é possível destacar uma tensão provocada por este artigo, decorrente do encontro entre a narrativa e as práticas discursivas dos profissionais das instituições que compõem a rede de enfrentamento à violência contra as mulheres. Por mais que ainda não se tenha certeza sobre qual o tipo de atenção mais adequado para o homem, a necessidade dessa atenção é considerada na fala de grande parte dos profissionais. Mais do que isso, é percebida como estratégica para o enfrentamento do problema da violência. O reconhecimento dessa necessidade parece ter sido concomitante à ampliação da compreensão sobre o que é violência contra as mulheres.

Se, em algum momento, a tipificação da violência foi instituída como sinônimo de agressão física, pode-se também sinalizar mais um movimento instituinte. A ampliação desse conceito foi uma conquista gradativa, que ocorreu de forma tão lenta quanto a mudança na legislação. Essa ampliação trouxe mais uma ruptura, à medida que retirou a violência contra as mulheres da seara dos crimes de menor potencial ofensivo e construiu, recentemente, uma legislação específica sobre $\mathrm{o}$ assunto.

O encontro da violência contra as mulheres e a saúde parece ter acontecido neste ponto: entre a ampliação do conceito e mudança na legislação. Primeiramente, foi nesse processo de ampliação de sentido que a violência foi posicionada também como um problema de saúde pública. Logo, se ao se tornar um problema público colocou-se como alvo de políticas sociais, ao se tornar um problema de saúde também precisou tornar-se como preocupação deste setor.

Programas foram formulados, serviços organizados, iniciando a tentativa de articulação de uma rede de enfrentamento. Contudo, ao que parece, os serviços de saúde ainda não constituem uma porta de entrada para casos de violência e seu lugar na Rede ainda é um tanto confuso. Quais ruídos se colocam nesse corredor de acesso às unidades de saúde para homens e mulheres envolvidos em situação de violência?

A associação entre violência e dependência química é recorrente e parece abrir as portas para uma compreensão mais ampla de ambas. Porém, se a presença desses homens pode ser percebida nos CAPs-ad, o problema com drogas parece minimizar tanto o ato de violência cometido como as possibilidades de discussão sobre o mesmo, uma vez que este ato muitas vezes nem mesmo é mencionado por quem encaminha o homem e, por conseguinte, pouquíssimo ou não discutido.

Falamos em homens. Mas, o que justificaria a dificuldade de acesso das mulheres? Parece que a compreensão ampliada da violência contra as mulheres e seu reconhecimento como um problema de saúde não conseguiram de fato imprimir uma ruptura no que continua sendo um problema de justiça e segurança pública. É assim que a violência contra as mulheres parece ser percebida, e isso é expresso pela conformação da rede de atenção a esse problema.

O que não foi ampliado? A compreensão da violência ou o conceito de saúde? É importante lembrar que 
o conceito de violência foi progressivamente desatrelado da noção de agressão física, e se passou a considerar também as dimensões psicossocial e institucional. Assim também o conceito de saúde foi historicamente ganhando novas roupagens. Saiu de uma dimensão biológica, material. Era a dimensão biológica que requeria uma intervenção medicamentosa, centrada na doença e meramente curativa. Construir outros sentidos para a saúde colocou a promoção de saúde como foco, a prevenção como estratégia.

O desenvolvimento desta pesquisa nos mostrou que, no jogo das práticas discursivas, a saúde é a biológica, a violência é a física e o gênero é o feminino. Ou seja, os serviços de saúde não são ainda porta de entrada para os casos de violência contra as mulheres, apenas para raros casos, vinculados a danos físicos. Tal constatação remete a um conceito de saúde ainda centrado na doença, no biológico, e, ao mesmo tempo, a um conceito de violência como dano físico. Estão em diálogo aí duas narrativas que pareciam ter sido rompidas. Logo, estamos diante de dois conceitos que foram ampliados mais nos atos legislativos e no plano das teorias do que na prática do setor saúde. E tal restrição parece se apresentar como obstáculo para concretização da integralidade.

A noção de integralidade é apresentada nesse momento, diante de tantos conjuntos de sentidos construídos e reconstruídos, como possibilidade e desafio de consolidação desses olhares ampliados. E, assim, como estratégia para enfrentamento de um problema que ainda persiste, mesmo tendo se tornado público e alvo de políticas. A centralização, seja no âmbito do setor saúde, seja na justiça e segurança pública, se apresenta como dissonante da perspectiva da integralidade e, por conseguinte, como obstáculo para a ampliação do entendimento tanto da saúde quanto da violência de gênero.

A integralidade se estabelece, portanto, também como possibilidade de lançar o olhar sobre os homens autores de violência, em suas necessidades de cuidado. E aqui reivindicamos o sentido da integralidade como valor, atrelada ao apelo à perspectiva de gênero, considerando-o relacional e performático e, ao mesmo tempo, desencadeador de marcas que, desatreladas do sexo, constroem expectativas e rupturas diante das dimensões masculinas e femininas nos mais variados processos sociais.

Não está se anunciando com isso que tais expectativas não possam existir. Ao contrário, certamente elas sempre existirão. O que não é possível é que continuem a servir para enclausurar homens e mulheres e sejam propulsoras de opressão, sofrimento e também de violência. O que é colocado como polarizado, dicotômico, precisa ser visto, em sua integralidade, como circular ou ainda espiral. Existe um entre no meio desses polos que parece constituir o ponto em que os encontros acontecem. Acontecem e transformam. Transformamse e acontecem.

É a partir da dialogia desse encontro que colocamos um ponto, que está longe de ser final; talvez uma vírgula, afinal a associação entre gênero e integralidade na proposição e execução de políticas públicas é apresentada apenas como um dos caminhos possíveis para a construção de um olhar mais amplo, condizente com a complexidade do problema em questão.

\section{Notas}

\section{${ }^{1}$ Apoio: CNPq/ CAPES \\ ${ }^{2} \mathrm{O}$ termo "agressor" foi amplamente utilizado pelo movimento feminista como estratégia na luta pela criminalização dos homens que cometem atos de violência contra as mulheres. Contudo, optamos por utilizar a expressão "homem autor de violência", por acreditar que, ao nomeá-lo "agressor", estamos reduzindo o autor ao ato de agressão cometido, cristalizando-o nesse lugar, tipificando-o. Neste texto, o uso do terno "agressor" se justifica, porém, quando faz referência ao modo como os textos e documentos fazem referência a esses homens. \\ ${ }^{3}$ Entre esses profissionais, incluem-se os autores deste artigo. \\ ${ }^{4}$ A Lei encontra-se disponível no site: http://www.planalto.gov. br/CCIVIL/Ato2004-2006/2006/Lei/L11340.htm \\ ${ }^{5}$ Os focos de análise a partir dos quais os repertórios são apresen- tados estão sublinhados, e a discussão transcorrerá a partir dos mesmos. Trata-se de uma tentativa de dar fluidez ao texto de análise, à medida que as categorias não se constituem como compartimentos estanques. Pelo contrário, os repertórios são compartilhados e elas se cruzam constantemente.}

${ }^{6}$ Nome fictício.

\section{Referências bibliográficas}

Barbieri, T. (1993). Sobre a categoria gênero: uma introdução teórico-metodológica. Recife: S.O.S. Corpo.

Biancarelli, A. (2006). Assassinatos de mulheres em Pernambuco: violência e resistência em um contexto de desigualdade, injustiça e machismo. São Paulo: Publisher.

Butler, J. (2001). El gênero em disputa: en feminismo y la subversión de la identidad. México: Paidós.

Cecílio, L. C. O. (2001). As necessidades de saúde como conceito estruturante na luta pela integralidade e equidade na atenção em saúde. In R. Pinheiro \& R. A. Mattos (Orgs.), Os sentidos da integralidade na atenção e no cuidado à saúde (pp. 113-126). Rio de Janeiro: UERJ/ Abrasco.

Figueroa, J. G. (2004). La representación de los varones en estudios sobre masculinidades y reproducción: un muestrario de reflexiones. In B. Medrado, M. Franch, J. Lyra, \& M. Brito (Orgs.), Homens: tempos, práticas e vozes (pp. 22-34). Recife: Instituto PAPAI/ Fages/Nepo.

Galindo, D. C. G. (1999). Dados cientificos como argumento: o caso da redução de parceiros sexuais em aids. Dissertação de Mestrado, Programa de Estudos Pós-Graduados em Psicologia Social (PUCSP), São Paulo. 
Gergen, K. J. (1994). The social constructionist movement in modern psychology. American Psychologist, 40(3), 266-275.

Hartz, Z. M. de A. \& Contandriopoulos, A. P. (2004). Integralidade da atenção e integração de serviços de saúde: desafios para avaliar a implantação de um "sistema sem muros". Cadernos de Saúde Pública, 20(2), S331-S336.

Ibañez, E. (1994). La construcción del conocimiento desde uma perspectiva socioconstrucionista. In Montero, M. (Org.), Conocimiento, realidad e ideologia (p. 39-48). Caracas: Asociación Venezueleana de Psicologia Social AVEPSO.

Mattos, R. A. (2001). Os sentidos da integralidade: algumas reflexões acerca de valores que merecem ser defendidos. In R. Pinheiro \& R. A. Mattos (Orgs.), Os sentidos da integralidade na atenção e no cuidado à saúde (pp. 39-64). Rio de Janeiro: Instituto de Medicina Social, Universidade do Estado do Rio de Janeiro/ABRASCO.

Mattos, R. A. (2004). A integralidade na prática (ou sobre a prática da integralidade). Cadernos de Saúde Pública, 20(5), 1411-1416.

Nascimento, P. G. (1999). "Ser homem ou nada": diversidade de experiências e estratégias de atualização do modelo hegemônico de masculinidade em Camaragibe/PE. Dissertação de Mestrado, Programa de Pós-graduação em Antropologia, Universidade Federal de Pernambuco, Recife.

Saffiotti, H. I. B. (2004). Gênero, patriarcado, violência. São Paulo: Editora Fundação Perseu Abramo.

Santos, C. M. \& Izumino, W. P. (2005). Violência contra as mulheres e violência de gênero: notas sobre os estudos feministas no Brasil. Estudios Interdisciplinários de America Latina y El Caribe. 16(1), 147-164.

Scott, J. (1995). Gênero: uma categoria útil para análise histórica. Recife: S.O.S. Corpo.

Souza Leão, L. M. (2005). Saúde do adolescente: atenção integral no plano da utopia. Dissertação de Mestrado, Curso de Pós-graduação em Saúde Pública, Centro de Pesquisa Aggeu Magalhães, Fundação Oswaldo Cruz, Recife.

Spink, M. J. (2004). Linguagem e produção de sentidos no cotidiano. Porto Alegre: EDIPUCRS.

Spink, M. J. \& Medrado, B. (1998). Produção de sentido no cotidiano: uma abordagem teórico-metodológica para a análise das práticas discursivas. In M. J. Spink (Org.), Práticas discursivas e produção de sentido no cotidiano: aproximações metodológicas (pp. 41-61). São Paulo: Cortez.

Spink, P. (2003). Pesquisa de campo em psicologia social: uma perspectiva pós-construcionista. Psicologia e Sociedade, $15(2), 18-42$.

Edna Granja é Mestre em Psicologia pela UFPE, atua como psicóloga no Centro de Apoio Psicossocial para usuários de álcool, fumo e outras drogas, CAPSAD, integrante do Núcleo de Pesquisas em Gênero e Masculinidades (Gema/UFPE). Coordenadora do

Núcleo Pernambuco da ABRAPSO. Endereço para Correspondência: Departamento de Psicologia - Av. dos Reitores, $\mathrm{s} / \mathrm{n}$. Centro de Filosofia e Ciências Humanas $(\mathrm{CFCH}), 9^{\circ}$ andar. Cidade Universitária. CEP: 50.670-901

Recife-PE.

Email: ednapsi@yahoo.com.br
Benedito Medrado é Doutor em Psicologia Social, professor adjunto do Departamento de Psicologia da UFPE, fundador do Instituto PAPAI, atual coordenador do Núcleo de Pesquisas em Gênero e Masculinidades (Gema/ UFPE). Integrante da Diretoria Nacional da Associação Brasileira de Psicologia Social (ABRAPSO) - 2008/09 e da Rede Feminista Norte-Nordeste de Estudos e Pesquisas sobre Mulher e Relações de Gênero (REDOR). Endereço Para Correspondência: Departamento de Psicologia - Av. dos Reitores, s/n. Centro de Filosofia e Ciências Humanas $(\mathrm{CFCH}), 9^{\circ}$ andar. Cidade Universitária. CEP: 50.670-901 Recife-PE. E-mail: beneditomedrado@uol.com.br

\section{Homens, violência de gênero e atenção integral em saúde} Edna Granja e Benedito Medrado

Recebido: 05/06/2008

$1^{\text {a }}$. Revisão: $28 / 10 / 2008$

Aceite final: 04/02/2009 